\title{
Commentary
}

Journal of Research in Interprofessional

Practice and

Education

Vol. 1.3

December, 2010

\section{Using Ethnographic Methods to Understand Change in Interprofessional Practice}

\section{Lesley Gotlib Conn, PhD}

This commentary provides additional background and rationale for the use of ethnographic methods to study and explain constructs related to interprofessional practice. In health services and health professions education research there is now firm recognition for the necessary use of qualitative methodology to develop contextually relevant, yet conceptually generalizable findings [1-4]. Many qualitative researchers use the terms ethnographic research or ethnography to describe both an overall research approach and the use of a range of qualitative methods, including observation, interviews, and document and archival analysis. Ethnography is traditionally characterized by 1) a sustained period of research in the field during which the researcher is immersed in the setting, to the extent possible, 2) participant or non-participant observation, which involves the ethnographer's attempt to understand the participants' world by actually participating in it, again, to the extent that this is possible, and 3 ) an operating principle of cultural relativism, that is, an attempt to see the world from the perspective of one's participants without judgment or bias from one's own worldview [5]. The ethnographer's data are collected in the form of field notes, best described as reconstructions and reflections of what s/he saw, did, and heard in the field, written-up in narrative, journal-like fashion [6]. Data analysis involves transforming these descriptions into explanations or interpretive accounts via the development of emergent themes and categories, the identification of negative evidence, also known as deviant cases, and the inductive process of discovering how and why participants make meaning of various social phenomena the way that they do [7].

However, the practice of ethnography is not homogeneous. The ethnographic tradition has a few different histories in different social science domains, such as sociology and anthropology, and is neither conceptualized nor carried out the same by everyone who purports to do it [8]. Ethnography in the anthropological tradition, for instance, might be regarded as relatively flexible in terms of its methodology when compared with ethnography typical in health services and health professions education research [9]. Therefore, as application of, and appreciation for, the principles of ethnography and qualitative research in this field continue to develop, it is important to recognize and be clear about the epistemological and methodological traditions that exist and which differentially inform the way ethnographic research is both carried out and translated to the wider audience.

The article "Creating Sustainable Change in the Interprofessional Academic Primary Care Setting: An Appreciative Inquiry Approach" draws from the disciplines of anthropology, organizational behaviour research, and communication studies to advance a conceptual model of change in interprofessional primary care 
302

Commentary: Ethnographic Methods to Understand Change

Gotlib Conn

Journal of Research in Interprofessional Practice and Education

Vol. 1.3 December, 2010 practice. An ethnographic approach was used for this longitudinal research because, first, there have been few attempts to use qualitative methods to explore the impact of interprofessional education (IPE) interventions in primary care, and second, we consequently know little about how effective interprofessional collaboration is actually enacted and changed in the practice setting [10]. The research team for this study felt that a robust understanding of these phenomena would more likely be developed through the use of observation and interview techniques employed by skilled ethnographers, rather than quantitative methods such as surveys, which have been more popular.

One way that ethnographers validate their findings is by using multiple data collection methods, a process also known as triangulation [11]. Triangulation of methods, data sources, theoretical frameworks, and/or researcher perspectives are techniques used to enhance the rigour of qualitative research. For the study described in the article, observations and interviews with Family Health Team (FHT) staff were used to confirm and disconfirm emergent findings; observations and interviews were conducted simultaneously to inform one another as the study proceeded. This exchange and synergism between the two methods occurred in an iterative fashion over the course of four months, guiding the research as it was carried out. For example, an initial set of scoping interview questions sought to explore staff experiences and perspectives on the effectiveness of the pre-FHT teamwork intervention: "Over the last two years as the FHT has evolved, what has your experience of teamwork been like?" "What factors have had the most important impact on your experience of teamwork?" In response to these very general questions, participants initially named the various concrete changes that had taken place, mainly the interprofessional meetings and committees that had been happening since the intervention that increased the frequency of interprofessional communication: daily clinic huddles, design teams, interprofessional case conferences. The ethnographer began to catalogue these new ways of doing things as evidence for change as reported by participants. It became clear that these "events" were the readily available examples of teamwork in the minds of FHT members. Observations around these significant events and ongoing informal interviews (i.e., guided conversations) with staff then explored further how the type and quality of communication, in addition to its frequency, may have shifted. Findings revealed that some staff felt the quality of communication had, in fact, changed very little, despite an increase in quantity. Thus, these techniques were used to triangulate participants' initial reports of experiencing more communication in the post-intervention period than they did prior. These additional data provided insights into the change in different dimensions of communication and the slower transformation of the wider FHT discourse of teamwork.

Ethnographic methods also allow the researcher to develop rapport with participants over time and afford the opportunity to gain a deeper knowledge of the study setting. Through non-participant observation in the FHT clinic, the ethnographer was eventually informed enough about local processes and norms to be able to effectively probe participants to talk about how they experience their work and 
303

Commentary: Ethnographic Methods to Understand Change

Gotlib Conn

Journal of Research in Interprofessional Practice and Education

Vol. 1.3

December, 2010 working relationships in the FHT. For example, a recurring comment from participants to the ethnographer was around the perception of a physician-centeredness and hierarchy of professions within the practice. Although this was not a new finding as compared to what emerged from data collected prior to the intervention [12], the use of ethnographic methods uncovered how participants' views of physiciancenteredness and hierarchy had shifted. Informal interviews probed participants for specific examples of what physician-centeredness and hierarchy now looked like and how it affected teamwork: "Can you give me an example of a recent time when you experienced the presence of the professional hierarchy?" Response to this question led to an emerging hypothesis that despite staff's initial reports of enthusiastic participation and professional representation at teambuilding events and committees, these were only surface-level changes in their interprofessional practice. Team transformation at a conceptual level, which involves transforming both behaviours and beliefs about hierarchical relations, is a very layered and complex process that has really only just begun.

The article offers a methodological and conceptual framework for advancing high quality research in interprofessional practice and education. Informed by the principles of ethnography, this case study of ongoing change in an interprofessional academic primary care setting can be used by other clinical practice groups in transformation to make meaning of their evolving teamwork experiences. We hope that readers will gain from both the practical and conceptual utilization of this research [3] and the methodological insights and lessons learned.

\section{References}

1. Kuper, A., Reeves, S., \& Levinson, W. (2008). Qualitative research: An introduction to reading and appraising qualitative research. British Medical Journal, 337, 404-407.

2. Atkinson, P., \& Pugsley, L. (2005). Making sense of ethnography and medical education. Medical Education, 39, 228-234.

3. Sandelowski, M. (2004). Using qualitative research. Qualitative Health Research, 14(10), 1366-1386.

4. Pope, C., \& Mays, N. (2009). Critical reflections on the rise of qualitative research. British Medical Journal, 339, 737-739.

5. Hammersley, M., \& Atkinson, P. (1995). Ethnography: Principles in practice, 2nd edition. London: Routledge.

6. Sanjek, R. (1990). A vocabulary for fieldnotes. In Sanjek, R. (Ed.), Fieldnotes: The makings of anthropology, (pp. 92-121). Ithaca: Cornell University Press.

7. Pope, C., Ziebland, S., \& Mays, N. (2000). Analysing qualitative data. British Medical Journal, 320, 114-116.

8. Atkinson, P., Coffey, A., Delamont, S., Lofland, J., \& Lofland, L. (Eds.). (2007). Handbook of ethnography. Los Angeles, London, New Delhi, Singapore: Sage Publications.

9. Sobo, E. J. (2009). Culture and meaning in health services research. Walnut Creek, CA: Left Coast Press.

10. Reeves, S., \& Goldman, J. (2006). Examining the nature of interprofessional ectucation in primary; icare: -A review of the titerature: Toronto:-University-of Foronto. URL: 'Lhttps://wwww.cihc.ca! /library/bitstream/10296/346/1/Reeves_IPEPrimaryCare.pdf_i'] October 21, 2010].

11. Creswell, J. W., \& Miller, D. L. (2000). Theory into practice, 39(3), 124-130.

12. Oandasan, I., Gotlib Conn, L., Lingard, L., Karin, A., Jakubovicz, D., Whitehead, C. et al. (2009). The impact of space and time on interprofessional teamwork in Canadian primary health care settings: Implications for health care reform. Primary Health Care Research \& Development, 10, 151-162. 